\title{
Investigation of the association between mean platelet volume and Helicobacter pylori gastritis
}

\author{
Abdullah Ozgur Yeniova ${ }^{1 *}$, Metin Kucukazman ${ }^{1}$, Naim Ata $^{2}$, Kurşad Dal ${ }^{2}$, Ayse Kefeli ${ }^{1}$, Hakan \\ Bulus $^{3}$, Kadir Okhan Akin ${ }^{4}$, Derun Taner Ertugrul ${ }^{5}$ and Yasar Nazligul ${ }^{1}$ \\ ${ }^{1}$ Department of Gastroenterology, Kecioren Teaching and Research Hospital, Ankara, Turkey. \\ ${ }^{2}$ Department of Internal Medicine, Kecioren Teaching and Research Hospital, Ankara, Turkey. \\ ${ }^{3}$ Department of General Surgery, Kecioren Teaching and Research Hospital, Ankara, Turkey. \\ ${ }^{4}$ Department of Clinical Biochemistry, Kecioren Teaching and Research Hospital, Ankara, Turkey. \\ ${ }^{5}$ Department of Endocrinology and Metabolism, Kecioren Teaching and Research Hospital, Ankara, Turkey.
}

Accepted 3 May, 2013

\begin{abstract}
Helicobacter pylori is one of the common infection of humans. It is associated with chronic gastritis, peptic ulcer, mucosa related tissue lymphoma and gastric cancer. Whether $\boldsymbol{H}$. pylori gastritis is a local inflammation or contributes to systemic inflammation remains unclear. Mean platelet volume is an indicator of systemic inflammation that can be determined from routine hemogram analyses. The present study was aimed to evaluate the relationship between mean platelet volume and $H$. pylori gastritis. Two hundred and eighty three (283) patients admitted with dyspeptic symptoms, and to whom endoscopy was performed, were enrolled in the study. Mean platelet volume levels of patients with and without $H$. pylori gastritis were compared and also, mean platelet volume levels according to parameters of Sydney Score System were compared. There was no significant difference between patients with and without $H$. pylori gastritis in the mean of mean platelet volume ( $p>0.05)$. Also, mean platelet volume levels did not differ between groups with regards to $H$. pylori intensity $(p>0.05)$. There was also no significant association between mean platelet volume levels and $H$. pylori gastritis intensity. Chronic and acute infection, atrophy and intestinal metaplasia also did not have relationship with mean platelet volume. It can be concluded therefore, that mean platelet volume cannot be used as an indicator of systemic inflammation for $\boldsymbol{H}$. pylori gastritis.
\end{abstract}

Key words: Mean platelet volume, Helicobacter pylori, inflammation.

\section{INTRODUCTION}

Helicobacter pylori is the most common bacterial infection of humans that is specific for gastric epithelial cells. It is a Gram negative, microaerophilic bacterium associated with chronic gastritis and peptic ulcer disease as well as gastric cancer and mucosa related tissue lymphoma (MALT) (McColl, 2010). Prevelance of $H$. pylori depends on geographical location and socioeconomical status but approximately $50 \%$ of the world adult population is infected by H. pylori (Pounder and Ng, 1995).

$H$. pylori colonizes the human stomach and triggers gastric inflammation. It promotes neutrophils and monocyte recruitment, and many proinflammatory cytokines which causes gastric mucosa damage release. Although, high prevalence of infection, small proportion of

*Corresponding author. E-mail: zgryeniova@yahoo.com.tr. Tel: +90 312 3569000. Fax: +90 3122213276.

Abbreviations: MALT, Mucosa related tissue lymphoma; MPV, mean platelet volume; CBC, complete blood count. 
population suffer from the gastroduodonal disease associated with $H$. pylori. Chronic infection and inflammation continues unless $H$. pylori is eradicated. Innate inflammatory response of organisms is not enough for eradication of $H$. pylori. Whether this inflammation is limited to gastric mucosa or causes systemic inflammation remains unclear.

As a result of high prevalence of $H$. pylori, association between other common diseases that is great of importance to public health has been addressed. Some studies reported the relationship between $H$. pylori infection and diabetes mellitus and coronary artery disease (Jha et al., 2008; Oldenburg et al., 1996).

Platelets play a crucial role in the development of cardiovascular events (Davi and Patrono, 2007). Mean platelet volume (MPV) is one of the platelet indices that marks platelet size. MPV is a routinely available laboratory analysis that can be determined from hemograms, thus, it has been assessed as an inflammatory indicator for various types of disease. High MPV values indicate larger and more active platelets which contribute to the thrombotic events. Some studies yielded higher MPV values for diseases assumed to have low grade inflammation such as diabetes mellitus and coronary artery disease (Cameron et al., 1983; Shah et al., 2012).

The aim of the present study was to evaluate the relationship between $H$. pylori infection and MPV as well as correlation between $H$. pylori and inflammation intensity and MPV.

\section{MATERIALS AND METHODS}

\section{Patients}

Patients who were admitted to Department of Gastroenterology, Keciören Training and Research were assessed. Two hundred and eighty three (283) patients with dyspeptic symptoms were recruited from gastroenterology outpatient clinic between during January and June 2012. Local ethical committee approved the study. Informed consent was given by individuals enrolled in the study. All patients were subjected to upper gastrointestinal system endoscopy and blood samples were collected for routine complete blood count (CBC). Exclusion criteria were, having diabetes mellitus, coronary artery disease, renal failure, liver failure, cardiac failure, inflammatory disease such as rheumatoid arthritis, systemic lupus erythematosus and malignancies.

\section{Methods}

During endoscopy, biopsies for histopathological analyses were obtained from antrum and corpus separately. $H$. pylori was diagnosed according to the positive staining with Giemsa and presence of curved-shaped bacteria on the epithelial cell surface. Hematoxylen eosin was used for routine histopathological examination evaluated by an experienced pathologist who is not aware of the clinical and laboratory data of patients. Besides, presence of $H$. pylori was reported for each specimen by the pathologist, $H$. pylori intensity was reported according to the Sydney System. Inflammation, intensity, intestinal metaplasia and atrophy were evaluated for each specimen as normal/absent (0), mild (1), moderate (2) and severe (3) (Dixon et al., 1996).

CBC was analyzed by automated blood cell counters. Venous samples were collected into EDTA containing tubes and measurements for $\mathrm{CBC}$ which were done within $2 \mathrm{~h}$ after sampling routinely in our hospital.

\section{Statistics}

Statistical Package for Social Sciences (SPSS) version of 15.0 was used for analysis. Data were tested for normal distribution using the Kolmogrov-Smirnov test. Continuous variables were given as means $\pm S D$. Mann Whitney $U$ was performed for comparing independent groups. Kruskal Wallis was used for variance between groups according to the HP intensity. Chi square was used for comparison of categorical variables. Spearman's rank order was used to assess the correlation between inflammation intensity, atrophy, intestinal metaplasia and MPV. When $p$ values were expressed as $<0.05$, analyses were accepted as significant.

\section{RESULTS}

A total of 283 patients were included in this study. One hundred and sixty nine, $169(59 \%)$ of them were female while $116(41 \%)$ of them were male. $168(59.4 \%)$ patients were diagnosed with HP infection, 115 of them do not have $\mathrm{H}$. pylori infection. $97(57.7 \%)$ of patients with HP infection were female and $71(42.3 \%)$ of them were male. $70(60.9 \%)$ of patients without $H$. pylori were female and $45(39.1 \%)$ of them were male. No significant difference was determined between patients with and without $H$. pylori infection in the term of gender $(p=0.59)$. Also, groups according to the $H$. pylori intensity do not have significant difference in terms of gender. Mean age of patients with $H$. pylori infection was $40.33 \pm 13.3$, while mean age of patients without $H$. pylori infection was $44.83 \pm 15.45$, there was no significant difference $(p=$ $0.16)$

MPV values of 283 patients were between 6.30 and $11.5 \mathrm{fL}$. Mean of the MPV was $8.55 \pm 0.93 \mathrm{fL}$. $9(3.2 \%)$ patients' MPV values were below the normal range and 4 (1.4\%) patients MPV value were higher than the normal range. Patients with and without $H$. pylori infection have similar mean MPV values. Mean of MPV of patients with $H$. pylori infection was $8.57 \pm 0.94$ while mean of MPV values of patients without $H$. pylori infection was $8.53 \pm$ 0.92 . There was no significant difference between two groups ( $p>0.05)$ (Figure 1). H. pylori intensity, acute inflammation, chronic inflammation, atrophy and intestinal metaplasia status were assessed for each of antrum and corpus samples. Highest values of the two region was determined by comparing assessments. When MPV values of groups according to the $H$. pylori intensity were compared, there was no significant difference $(p=0.46)$ (Table 1). Correlation between acute and chronic inflammation intensity, atrophy, intestinal metaplasia and MPV levels were not found to be statistically significant ( $>0.05)$ (Table 2). 


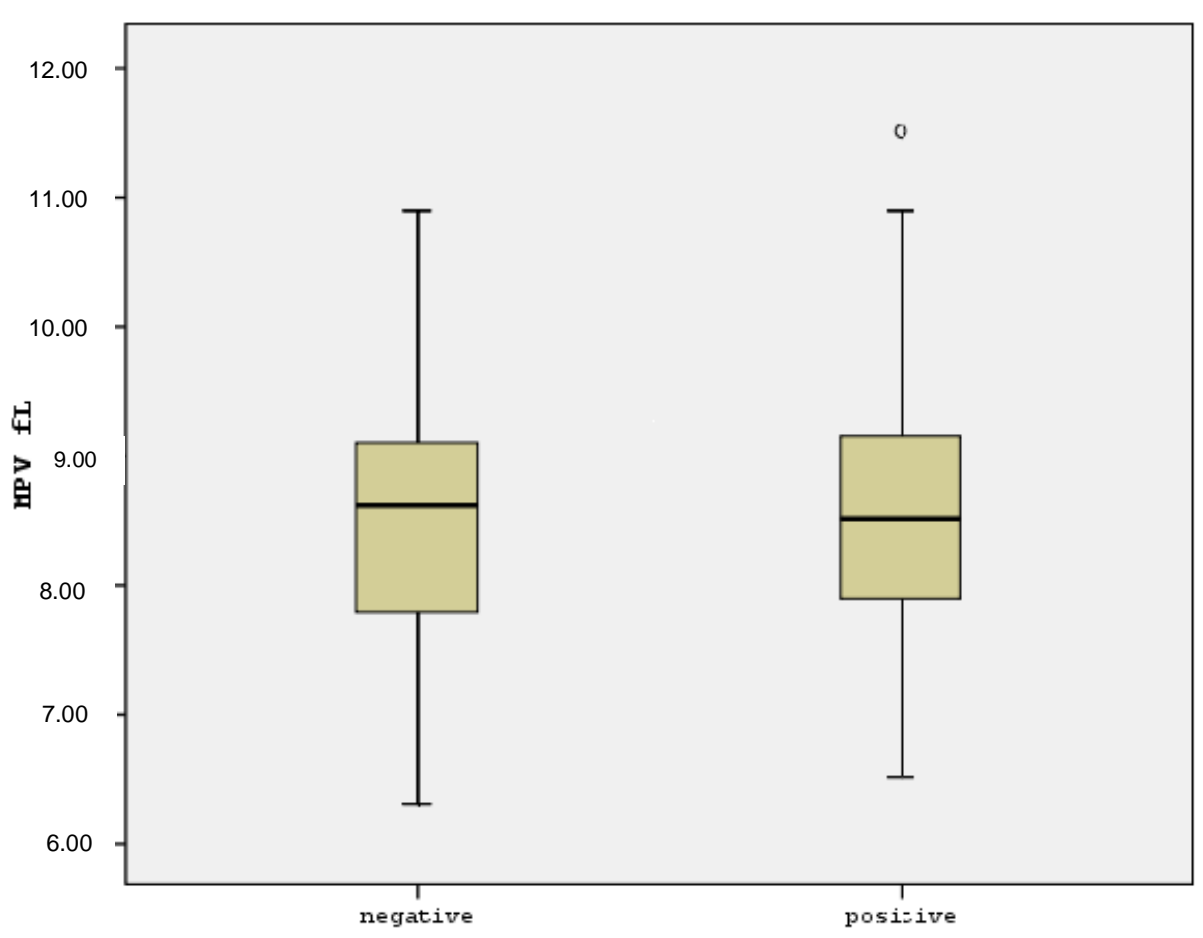

Helicobacter pylori infection

Figure 1. Absence of relationship between MPV levels and HP gastritis.

Table 1. Comparison of MPV levels of groups according to the HP intensity.

\begin{tabular}{ccc}
\hline HP intensity & MPV (fL, mean \pm SD) & Patient number \\
\hline 0 & $8.51 \pm 0.91$ & 116 \\
1 & $8.46 \pm 0.83$ & 69 \\
2 & $8.64 \pm 1.08$ & 72 \\
3 & $8.78 \pm 0.8$ & 26 \\
\hline
\end{tabular}

Table 2. Correlation between MPV levels, acute and chroinc inflammtion intesity.

\begin{tabular}{lcc}
\hline Parameter & $\mathbf{r}$ (coefficient correlation) & $\mathbf{p}$ \\
\hline Neutrophil & 0.066 & 0.268 \\
Mononuclear cell & 0.055 & 0.353 \\
Atrophy & 0.012 & 0.838 \\
Intestinal metaplasia & -0.066 & 0.267 \\
\hline
\end{tabular}

\section{DISCUSSION}

In this study, we hypothesized that MPV; a putative marker for inflammation can reflect the gastric inflammation as well as systemic low grade inflammation. No significant difference have achieved between patients with and without $H$. pylori infection. Furthermore, there was no difference between groups according to HP intensity. MPV did not correlate with any parameters of Sydney System. Acute and chronic inflammation, atrophy and intestinal metaplasia is not related to the MPV level.

HP infection of gastric mucosa is characterized by recruitment of neutrophil cells which usually progress to chronic inflammation caused by mononuclear cells (Stolte et al., 1995). Because of the inflammation in the gastric mucosa, it is thought that HP infection may lead to syste- 
mic inflammation. $C$ reactive protein $(\mathrm{CRP})$, tumor necrosis factor $\alpha$ (TNF- $\alpha$ ) and interleukin 6 (IL-6) are the markers of low grade chronic inflammation (Silha et al., 2007). Both clinical trails and population based epidemiologic studies achieved conflicting results about blood levels of inflammation markers in HP infection. Some studies have reported increased levels of CRP in HP infection (Gen et al., 2010; Stettin et al., 2008), whereas one clinical trial was found with no correlation between HP infection and CRP (Gillum, 2004). One large population based epidemiological study found relationship between HP infection and CRP but the other ones did not reiterate this result (Jackson et al., 2009; Nazmi et al., 2010).

Serum levels of other inflammatory cytokines have been researched. TNF- $\alpha$ which plays a pivotal role in gastric inflammation has increased in patients with HP infections (Perri et al., 1999). Russo et al. (2001) determined increased levels of IL-8 and TNF- $\alpha$ but not IL10 and IFN- $\gamma$ in asymptomatic persons infected with HP when compared with persons without HP infection. On the other hand, Fan et al. (1995) did not find higher serum levels of IL-8 and TNF- $\alpha$ in patients with HP infection. Correlation between IL-6, IL-8, TNF- $\alpha$; between HP intensity and severity of inflammation has been shown in a study. No correlation was found between these parameters and inflammatory markers (Bayraktaroglu et al., 2004).

Cardiovascular disease and related factors like type 2 diabetes, insulin resistance and obesity are associated with a state of chronic low grade inflammation. Some epidemiologic studies have shown relationship between chronic HP infection and coronary artery disease (Mendall et al., 1994; Strachan et al., 1998). Chronic infection that persists in the organisms may trigger the atherosclerosis by vascular inflammation, infection of blood cells and endothelial dysfunction (Jia et al., 2009).

It was shown that HP infection causes leukocyteplatelet activation and aggregation in gastric venules of murine model (Elizalde et al., 1997). Same study reported that HP infected humans have circulating platelet aggregates and activated platelets that suggests microvascular dysfunction may contribute to the non gastrointestinal manifestations of HP infection. One study reported that eradication of HP can improve endothelial dysfunction measured by ankle brachial index and flowmediated diameter percent change (Blum et al., 2011).

In the last decades, growing evidence implicates the role of the platelets in thrombosis, inflammation, immunity and angiogenesis. MPV is a marker of platelet size that can be easily found from hemograms. Larger platelets mean metabolically and enzymatically more active platelets that contribute to proinflmaamatory and prothrombotic states (Chu et al., 2010). Elevated MPV levels have been associated with myocardial infarction and related mortality (Endler et al., 2002). Intensity of systemic inflammation identifies the size of the platelets.
High grade inflammatory conditions like rheumatoid artritis and inflammatory bowel disease is characterized by small sized platelets thus decreased level of MPV (Kapsoritakis et al., 2001; Kisacik et al., 2008). MPV levels and disease activities have inverse relationships. Disease achieved remission with immunosuppressive therapy is characterized by higher MPV levels than active period of the disease.

To the best of our knowledge, this study is the largest in the literature that investigated correlation between HP infection and MPV levels. Topal et al. (2010) conducted a study that includes 114 consecutive patients. MPV levels did not differ according to the parameters of updated Sydney Score. Also, antrum, corpus and incisura angularis specimens were evaluated separetely, there were no correlation between MPV and HP intensity, acute and chronic inflammation, atrophy and intestinal metaplasia (Topal et al., 2010). Our study reiterates the results of this study.

The regulation of megakaryocytopoiesis is linked to the circulating platelets and physiological and pathological conditions affect this process. Inflammatory cytokines including thrombopoetin, granulocyte-macrophage colony stimulating factor, IL-1, IL-6, TNF- $\alpha$ influences maturation and release of platelets into the circulation. One of the possible explanation that MPV levels did not correlate with HP intensity is difference of cytokines involving in the inflammation of gastric mucosa. Although, serum levels of TNF- $\alpha$ increased in HP infection, notable cytokine of gastric inlammation is IL-8. One study reported that IL-6 levels that have impact on platelet production did not differ between patients with and without HP infection (Blum et al., 2011). But the same study reveals the reversibility of endothelial dysfunction after HP eradication.

Another reason for the finding of this and previous study is that HP infection is a local infection rather than systemic. Although, gastric microvascular architecture is damaged because of platelet aggregation and activation, it is not enough to trigger a systemic inflammation. Larger vessels of host must be chronically infected for endothelial dysfunction. HP associated non gastrointestinal disease like coronary artery disease and diabetes pathogenesis does not seem to be related to platelet aggregation. HP infection can cause epithelial dysfunction by altering levels of lipid profile. One study reported that HP infected individuals' have increased level of LDL and HOMA-IR and the levels decrease after eradication (Goll et al., 2007). Küçükazman et al. (2009) reported correlation between LDL-C and triglycerides levels and updated Sydney Score System.

In conclusion, the relationship between chronic infection, inflammation and diseases like coronary artery disease and diabetes mellitus remains unclear. MPV cannot be an indicator of gastric inflammation in this situation. As protection from this disease depends on early recognition, discovering indicators of inflammation 
has great importance. Large prospective studies are needed to explain this subject.

\section{REFERENCES}

Bayraktaroglu T, Aras AS, Aydemir S, Davutoglu C, Ustundag Y, Atmaca H, Borazan A (2004). Serum levels of tumor necrosis factoralpha, interleukin-6 and interleukin-8 are not increased in dyspeptic patients with Helicobacter pylori-associated gastritis. Mediators Inflamm. 13(1):25-28.

Blum A, Tamir S, Mualem K, Ben-Shushan RS, Keinan-Boker L, Paritsky M (2011). Endothelial dysfunction is reversible in Helicobacter pylori-positive subjects. Am. J. Med. 124(12):11711174.

Cameron HA, Phillips R, Ibbotson RM, Carson PH (1983). Platelet size in myocardial infarction. Br. Med. J. (Clin. Res. Ed.) 287(6390):449451.

Chu SG, Becker RC, Berger PB, Bhatt DL, Eikelboom JW, Konkle B, Mohler ER, Reilly MP, Berger JS (2010). Mean platelet volume as a predictor of cardiovascular risk: a systematic review and metaanalysis. J. Thromb. Haemost. 8(1):148-156.

Davi G, Patrono C (2007). Platelet activation and atherothrombosis. N. Engl. J. Med. 357(24):2482-2494.

Dixon MF, Genta RM, Yardley JH, Correa P (1996). Classification and grading of gastritis. The updated Sydney System. International Workshop on the Histopathology of Gastritis, Houston 1994. Am. J. Surg. Pathol. 20(10): 1161-1181.

Elizalde JI, Gomez J, Panes J, Lozano M, Casadevall M, Ramirez J, Pizcueta P, Marco F, Rojas FD, Granger DN, Pique JM (1997). Platelet activation in mice and human Helicobacter pylori infection. J. Clin. Invest. 100(5):996-1005.

Endler G, Klimesch A, Sunder-Plassmann H, Schillinger M, Exner M, Mannhalter C, Jordanova N, Christ G, Thalhammer R, Huber K, Sunder-Plassmann $R$ (2002). Mean platelet volume is an independent risk factor for myocardial infarction but not for coronary artery disease. Br. J. Haematol. 117(2):399-404.

Fan XG, Chua A, Fan XJ, Keeling PW (1995). Increased gastric production of interleukin-8 and tumour necrosis factor in patients with Helicobacter pylori infection. J. Clin. Pathol. 48(2):133-136.

Gen R, Demir M, Ataseven H (2010). Effect of Helicobacter pylori eradication on insulin resistance, serum lipids and low-grade inflammation. South. Med. J. 103(3):190-196.

Gillum RF (2004). Infection with Helicobacter pylori, coronary heart disease, cardiovascular risk factors, and systemic inflammation: the Third National Health and Nutrition Examination Survey. J. Natl. Med. Assoc. 96(11):1470-1476.

Goll R, Gruber F, Olsen T, Cui G, Raschpichler G, Buset M, Asfeldt AM, Husebekk A, Florholmen J (2007). Helicobacter pylori stimulates a mixed adaptive immune response with a strong T-regulatory component in human gastric mucosa. Helicobacter 12(3):185-192.

Jackson L, Britton J, Lewis SA, McKeever TM, Atherton J, Fullerton D, Fogarty AW (2009). A population-based epidemiologic study of Helicobacter pylori infection and its association with systemic inflammation. Helicobacter 14(5):108-113.

Jha HC, Prasad J, Mittal A (2008). High immunoglobulin A seropositivity for combined Chlamydia pneumoniae, Helicobacter pylori infection, and high-sensitivity $\mathrm{C}$-reactive protein in coronary artery disease patients in India can serve as atherosclerotic marker. Heart Vessels 23(6):390-396.

Jia EZ, Zhao FJ, Hao B, Zhu TB, Wang LS, Chen B, Cao KJ, Huang J, Ma WZ, Yang ZJ, Zhang G (2009). Helicobacter pylori infection is associated with decreased serum levels of high density lipoprotein, but not with the severity of coronary atherosclerosis. Lipids Health Dis. 8:59.
Kapsoritakis AN, Koukourakis MI, Sfiridaki A, Potamianos SP, Kosmadaki MG, Koutroubakis IE, Kouroumalis EA (2001). Mean platelet volume: a useful marker of inflammatory bowel disease activity. Am. J. Gastroenterol. 96(3):776-781.

Kisacik B, Tufan A, Kalyoncu U, Karadag O, Akdogan A, Ozturk MA, Kiraz S, Ertenli I, Calguneri M (2008). Mean platelet volume (MPV) as an inflammatory marker in ankylosing spondylitis and rheumatoid arthritis. Joint Bone Spine 75(3):291-294.

Kucukazman M, Yavuz B, Sacikara M, Asilturk Z, Ata N, Ertugrul DT, Yalcin AA, Yenigun EC, Kizilca G, Okten H, Akin KO, Nazligul Y (2009). The relationship between updated Sydney System score and LDL cholesterol levels in patients infected with Helicobacter pylori. Dig. Dis. Sci. 54(3):604-607.

McColl KE (2010). Clinical practice. Helicobacter pylori infection. N. Engl. J. Med. 362(17):1597-1604.

Mendall MA, Goggin PM, Molineaux N, Levy J, Toosy T, Strachan D, Camm AJ, Northfield TC (1994). Relation of Helicobacter pylori infection and coronary heart disease. Br. Heart. J. 71(5):437-439.

Nazmi A, Diez-Roux AV, Jenny NS, Tsai MY, Szklo M, Aiello AE (2010). The influence of persistent pathogens on circulating levels of inflammatory markers: a cross-sectional analysis from the MultiEthnic Study of Atherosclerosis. BMC Public Health 10:706.

Oldenburg B, Diepersloot RJ, Hoekstra JB (1996). High seroprevalence of Helicobacter pylori in diabetes mellitus patients. Dig. Dis. Sci. 41(3):458-461.

Perri F, Clemente R, Festa V, De Ambrosio CC, Quitadamo M, Fusillo M, Grossi E, Andriulli A (1999). Serum tumour necrosis factor-alpha is increased in patients with Helicobacter pylori infection and CagA antibodies. Ital. J. Gastroenterol. Hepatol. 31(4):290-294.

Pounder RE, $\mathrm{Ng} D$ (1995). The prevalence of Helicobacter pylori infection in different countries. Aliment. Pharmacol. Ther. 9 Suppl 2:33-39.

Russo F, Jirillo E, Clemente C, Messa C, Chiloiro M, Riezzo G, Amati L, Caradonna L, Di Leo A (2001). Circulating cytokines and gastrin levels in asymptomatic subjects infected by Helicobacter pylori $(H$. pylori). Immunopharmacol. Immunotoxicol. 23(1):13-24.

Shah B, Sha D, Xie D, Mohler ER, 3rd, Berger JS (2012). The relationship between diabetes, metabolic syndrome, and platelet activity as measured by mean platelet volume: the National Health And Nutrition Examination Survey, 1999-2004. Diabetes Care 35(5):1074-1078.

Silha JV, Nyomba BL, Leslie WD, Murphy LJ (2007). Ethnicity, insulin resistance, and inflammatory adipokines in women at high and low risk for vascular disease. Diabetes Care 30(2):286-291.

Stettin D, Waldmann A, Strohle A, Hahn A (2008). Association between Helicobacter pylori-infection, C-reactive protein and status of $B$ vitamins. Adv. Med. Sci. 53(2):205-213.

Stolte M, Stadelmann O, Bethke B, Burkard G (1995). Relationships between the degree of Helicobacter pylori colonisation and the degree and activity of gastritis, surface epithelial degeneration and mucus secretion. Z. Gastroenterol. 33(2):89-93.

Strachan DP, Mendall MA, Carrington D, Butland BK, Yarnell JW, Sweetnam PM, Elwood PC (1998). Relation of Helicobacter pylori infection to 13-year mortality and incident ischemic heart disease in the caerphilly prospective heart disease study. Circulation 98(13):1286-1290.

Topal F, Karaman K, Akbulut S, Dincer N, Dolek Y, Cosgun Y, Yonem $\mathrm{O}(2010)$. The relationship between mean platelet volume levels and the inflammation in Helicobacter pylori gastritis. J. Natl. Med. Assoc. 102(8):726-730. 